\title{
Adenosarcoma pN1 TNM Finding v7
}

National Cancer Institute

\section{Source}

National Cancer Institute. Adenosarcoma pN1 TNM Finding v7. NCI Thesaurus. Code C89625.

Regional lymph node metastasis. (from AJCC 7th Ed.) 